\section{ORIGITAL COMnTUMTCATIOTS.}

\section{ON THE PRACTICAL RESULTS OF QUARANTINE.}

\section{By T. SPENCER WELLS, F.R.C.S., Surgeon to the Samaritan Hospital.}

[Read at the Meeting of the Epidemiological Society, Aug.7th.]

Praras I I may be permitted to explain the circumstances - which have induced me to bring the subject of Quarantine again forward for consideration. Last year Dr. Milroy read a paper before this Society on the "Results of Quarantine in British Ports". This paper has since been published, and has led to a reply from Sir William Pym, which was also read before this Society at the meeting in June. After Sir William Pym's paper had been read, Dr. Milroy and Dr. Gavin (who had evidently studied it before it was read before the Society) replied at very considerable length ; and several members, including myself, deeming the subject too important to be dismissed without further discussion, it was arranged that I should reintroduce it by means of a short paper, as the rules of the Society do not permit the adjournment of a debate. I trust, therefore, that these circumstances may be accepted as an excuse for the hasty and fragmentary manner in which this paper is drawn up, my intention being simply to make such comments upon the papers and speeches of Sir Wm. Pym, Dr. Milroy. and Dr. Gavin, as may lead to a full discussion of an important public question, and probably elicit such an expression of the opinion of the Society as may influence the government of the country in future legislative enactments.

As some excuse for venturing to ask the attention of the Society to the statements I think it right to lay before them, I may state that I passed the greater part of the thirteen years from 1841 to 1853 in the Mediterranean, or in the countries upon its shores; that I spent one winter in Egypt, some weeks in Turkey, several months in different parts of Greece; and that I have inspected almost every lazaretto of any consequence in our own possessions in the Mediterranean, as well as those in Spain, Italy, Greece, Egypt, and Turkey; that my attention was early called to the subject of quarantine regulations in the Mediterrancan; and that, as I have been in frequent correspondence, not only with our own government, but with those of other countries, upon this subject, I may claim some share in the modifications which have been introduced in the quarantine laws since 1811. At my suggestion, Captain Casolani, of the Quarantine Department of Malta, had an interview with Mehemet Ali, and impressed upon that ruler that the true way to open his dominions to the free commerce of Europe was not by attempting to induce European governments to incur the risk of the importation of plague, but by endeavouring to annihilate the disease in his own dominions. This led to the adoption of sanitary measures in Egypt, to which I may hereafter allude. I have said this to prove that those who think a rational system of quarantine necessary for the public safety and tranquillity are among the most earnest advocates of those measures which are calculated to remove preventible causes of disease, and that I am not disqualified from treating this subject by want of acquaintance with the practical operation of quarantine regulations.

I do not intend to enter into the debateable question of the contagion or infection of plague or yellow ferer. I believe these diseases, under certain circumstances, to be as certainly propagated from one person to another as smallpox or scarlatina. But this is not the question before us; all we have now to determine is the effect of quarantine regulations upon their propagation. If we can show that their propagation is modified by these regulations, the question of contagion becomes one of mere theory, which the prection man misy leare open.
Quarantine regulations include a system of observation of persons arriving in healthy places from other places where diseases supposed to be contagious or infectious are prevalent, or are suspected to prevail: and, secondly, a system of separating the sick from the healthy in places where an epidemic prevails.

Now, with regard to the spread of the plague in Malta in 1813, of which epidemic Dr. Milroy has given a very partial account to the Society, I shall not dwell much upon the first portion of this system, although I think the case a very strong one in favour of the importation of disease. Here are the facts, so far as I could make them out by careful inquiry on the spot, and by consulting parliamentary documents, other official papers, and various writers of the period on both sides of the question. I will read them from an article I wrote in the year 1843, which appeared in the British and Foreign Medical Review.

Many of the cases in which a disease is said to have been imported are questioned, because the places into which the disease is said to have been imported are subject to occasional visitations of the pestilence, independent of any such importation; in other words, the disease is endemic in such places. But no such objection can be urged as to the island of Malta, "a dry rock of limestone, free from any source of malaria which could be conceived possible the give origin to the disease. In 1813 this island had bec 7 se from plague for $a$ hundred and thirty years, when a ship arrived on the 29th of March from Alexandria, where the plague was raging at the time of her departure, and she had lost two men by plague during the passage. Three days after her arrival in Malta, the master also died, the ship lying in the harbour close to the city of Valetta. The inhabitants became very uneasy, and some merchants remonstrated against the ressel remaining in the harbour; and Sir A. B. Faulkner, at that time physician to the forces in the island, addressed an official letter to the commander-in-chief, recommending the immediatc removal of the vessel. This was not attended to, and, on the 16th of April, six days after this admonitory letter was voritten, the first case of plague occurred in Valetta. (Evidence of Sir A. B. Faulkner, Parliamentary Report, pp. 46.)"

To say the least, this is a strong case; but I admit that the evidence is not entirely demonstrative. The results of the second part of the system, however-the segregation of the sick from the healthy-are quite conclusive as to the practical good derived from quarantine. If we can show that large bodies of people who are separated from others among whom some specific disease is prevailing are protected from that disease, no unprejudiced person can entertain doubts as to the beneficial results of segregation; and I contend that we can prove this by referring to the epidemic of plague in Malta in 1813, because "the inhabitants of the different districts differ so little from each other as to the circumstances of their soil, climate, or customs. In this island, during the plague of 1813 , when, out of a population of about $90,000,4,486$ deaths took place between April and November, we find that a whole city, 'shut up', enjoyed perfect immunity. Any one who will glance at a map of Valetta, and the smaller cities to the south of the harbour, will see that the distance from the point of Isola to Valetta is only $\mathbf{3 6 0}$ yards. This town differs in no respect from its neighbour, Vittorioso; both are surrounded by the sea on three sides, and have strong fortifications on the land side. The plague was raging at Vittorioso; it was raging in Cospicua, immediately beneath the walls fortifying the land side of Isola ; but not one single case occurred in this large city (Isola) during the whole period of the epidemic. The place was the residence of many old masters of merchant ressels, who had been engaged in the Levant trade, and therefore accustomed to plague precautions; and they, with the assistance of their townsmen, without government aid, completely severed their city from the rest of the island, admitting no person or thing without expurgation, enforcing the most rigid quarantine, and carefully guarding the place night and day. Now this town enjoyed a total exemption from the plague; a monument to the Virgin, 
commemarative of this fact, stands in the central square to this day; and an annual religious ceremony is regularly observed. Here is an instance, then, of a plague kept out of a town by means of separation: the same epidemic furnishes us with another instance in which it is kept within nother by similar means. The village of Curmi, situated at the head of the grand harbour, suffered severely from the plague; and when the diserse was on the decline at Valetts, Sir Thomas Maitland had this village surrounded by a wall and a series of sentinels. This cordon became gradually contracted, leaving part of the village free from restriction; and in this part alone was there plague in Malta when Sir Thomas Maitland admitted the rest of the island to free intercourse. He publicly proclaimed the plague extinct when he had shut it up within these lines, while the disease was raging within a mile of the capital; and no fresh case of plague afterwards took piace. Here, then, is plague surrounded in a village of a small island, the rest of the inhabitants of that island following their usual avocations, and not one receiving the disease. Another remarkable case, showing the effects of segregation, occurred in the convent of St. Augustine, which had been in strict quarantine until a servant purchased some old clothes from an infected district, and was taken ill. A monk who volunteered to attend him was placed with him in a separate apartment, and these two died, but no other individual within the walls. At Moscow, in 1770-1, the Foundling Hospital 'shut up', and the inmates, 1400 in number, were completely secluded. Some workmen, who got over 'the fences in the night time, were the only persons attacked; and these bcing immediately separated, the contagion did not spread, although more than 100,000 persons fell victims to this pestilence in other parts of the city.' (Williams, p. 282.) At Marseilles, in 1720, the religious houses which 'shut up' were exempt; the bishop certified that 'the plague has not penetrated into the religious communities which had not held any communication with persons without.' (Williams, p. 282) The Naval Hospital in Malta was strictly insulated, and the only case that occurred was in the person of the market-man, who had strayed into an infected family. The inmates of the prisons, nunneries, and convents, with the exception of the case just mentioned, had an entire immunity ; and the proportion of cases among the military was much less than among the remainder of the population. The Sicilian regiment, which adopted strict precautions, only lost one man, who had strayed into the town; and the other regiments which adopted similar regulations, though less strictly enforced, only lost twenty of a force of 4,000 , a proportion thirty times less than that of the general population.

"Here then are facts, positive facts, established beyond the possibility of question, by accurate observers and faithful recorders."

The same results have been observed in countries where plague is endemic. For instance, in Dr. Grassi's report, published in the correspondence on Quarantine Regulations, printed by order of the House of Commons in 1842, he says that, "during the plague in Alexandria, in 1834, the squadron of 16,000 persons remained perfectly well, and this not on account of removal from the seat of infection, because other ships in the same situation, which had communication with the shore, lost many persons. The arsenal, with 6,000 labourers, was situated close to the infected quarters, but kept in strict quarantine. During six to seven months, five or six cases of sudden death occurred, but no decided case of plague. The marine hospital, although surrounded by three villages which were completely deserted from the effects of plague, 'remained healthy during the long time that the plague lasted, only because a strict quarantine was maintained within its limits. The contrary took place at the land hospital.' (Parliamentary Report, p. 448.) The land hospital was very farourably situated, but the physician was a non-contagionist, did not adopt precantionary measures, and the diseace 'carried off many victims, and subjected the government to great acri- fices.' (I6. p. 448.) During the plagee, the collage with its hospital, the populous harem of the viceroy, other inferior establishments, and numerous privato families who shut up, escaped entirely; while of the Turks, who took no such precautions, it is said, "Then the malady declined, more than a hundred keys were found at the police office, of houses where the inhabitants had all perished." Dr. Grassi adds: "In the short period of two months, I saw fifty-seven dead bodies brought out of the house of a Turk, the treasurer-general of the navy." (I6. p. 448.) Dr. Chaotani Bey gives the numbers of those who were segregated during this pestilence, stating, "that in 32,525 individuals isolated in quarantine, not one case of plague has been proved." (Ib. p. 514.)

Again, according to Dr. Lachèze's report to the French Academy, he observed that in the epidemics of plague at Alexandria and Cairo, in 1835, some persons who had been isolated were affected by the disease, but only in the proportion of 1 to 400 ; while 1 in 3 of those who lived in free pratique were destroyed. This difference could not be explained by any superiority of social condition.

I conclude that all this must be accepted as some proof of practical good resulting from quarantine regulations in a district affected by an epidemic disease. I think I shall be able to show that they are not less useful in protecting healthy places; in other words, that they have kept out disease. I might go into details upon the occurrences that preceded the outbreak of any epidemic of plague in any European port which has been ravaged by it; and I could show that in every instance the outbreak had followed the arrival of diseased persons. The old reply would of course be offered, that these were mere coincidences, and that the arrival of a plague patient in a healthy sea-port had nothing whaterer to do with the disease which followed his arrival, but that this was owing to some foul drain or open sewer, which had certainly been in existence for jears and years before and since without producing plague, but which, just at the time of the arrival of the infected person, had become endowed with some unusual virulence, in consequence of some assumed change in the condition of the atmosphere. This is the so-called argument used by many who affect to lecture others upon what they term inconsequential reasoning. Fortunately the facts remain uncontroverted, however they may be explained away; and we have numerous instances of Marseilles, Malta, Genoa, Leghorn, and other places not subject to plague, remaining free from it for long series of years, and becoming devastated by it soon after the arrival of persons from infected countries. Let us now see what follows the arrival of such persons, when, instead of communicating with the unaffected inhabitants, they are segregated by quarantine authorities within the walls of a lazaretto.

A letter was published in 1841, by Dr. Pezzoni, upon the cases of plague which had occurred in the lazaretto of Constantinople. Dr. Davy, who wrote a long book, containing a chapter on Turkey and the system of quarantine, in which he has strongly supported the case of the non-contagionists, allows in a foot note (Davy, p. 122), that "it carried conviction to my mind, previously in doubt on the question." "The facts are shortly these: On June 8, 1841, a merchant vessel arrived at Constantinople from Alexandria, with some cases of plague among the passengers and crew. Constantinople and the neighbourhood had been free from plague for three years previously. A lazaretto guardian in perfect health was sent on board, and assisted in landing the patients. He was taken ill on the 13th, and died on the 15th, with bubo and every symptom of plague. A porter also, on the $22 n d$, was found to have had symptoms of plague for two days, and a very large bubo in the left groin followed. He was conveyed to the pest-house, and recorered. Two other employes of the lazaret died on the 15th and 17th of July. Here, then, we have a city of 800,000 inhabitants, free from epidemic influence; bealthy persons are placed in contact with plague patients, four take the diseses, and three die. The disease is confined within the walls of the lazaret, no one but those brought into connexion with lw- 
fected persons suffer: and the city has since remsined hellthy.

* Bimilar facts are related by Dr. Gravagna. On the 26th of May, 1841, a ressel arrived in Malta from Alexandria, with plague on boand among the sailors and pilgrims: The whole crew, etc., of the ressel, with guardians and two boatmen who had communicated with the pilgrims were segregated, and every precsution taken to prevent the spread of the disease. Cases appeared among the crew on the 4th and 6th of June, making in all ten cases, one showing itself during the voyage, and nine others in lazaret. One of the Maltese boatmen communicated with the ressel on the 28th of May, and on the 6th of June he was attacked by plague, with carbuncle and bubo, and died on the 10th. The other bostman was not attacked, nor were the guardians. Here, then, we see that the only man of a large population attacked by the disease, was one who was brought into contact with the diseased. He was confined in the lazaret, and the disease did not extend bejond the walls. Dr. Gravagna refers to a similar instance in 1821 , when an infected vessel arrived from Alexandria, and thirteen of its crew or passengers died of plague in the lazaretto. A Maltese who had had the disease in 1813, believed himself invulnerable, and voluntered to be a nurse, but after eight days he had symptoms of plague with bubo. He recovered, and, as in 1841, the disease was confined to the lazaretto."

A report was furnished to the French Minister of Commerce by M. Ségur-Dupeyron, in which he shows that in sixty-five cases, where plague was clearly the result of maritime importation, it broke out in fifty vessels during the royage. Dr. Aubert, in a memoir read before the Academy of Sciences in Paris, September 1841, states that "in the space of a hundred and twenty-four years, sixty-four vessels having plague on board have arrived in the lazaretti of Europe, and that in twenty-six only has the disease continued after the arrival; that it has never shown itself after the arrival, unless it had previously appeared during the passage; and that the period of latency has ncver exceeded eight days from the date of departure."

From Dr. Grassi's report, I before quoted, it appears that between 1831 and 1837, the plague has reached the port of Alexandria ten times from without; that it has been eight times subdued in the lazaretto; "and that in the two instances in which it passed into the country, the cause was the non-adoption of similar regulations."

I will not take up the time of the Society by enumerating other cases, but would refer the sceptical to the report to the Royal Academy of Medicine in Paris, in 1846, of a Commission appointed to inquire into the subject of plague and quarantine. They will see in that report, and in the documents and discussion by which it is accompanied, ample grounds for the following conclusion, at which the Commission arrived: "It is incontestable that the plague is transmissible beyond epidemic foci, both in ships at sea and in the lazarettoes of Europe." "The plague is not only transmitted on board ship, among persons leaving the same shores, breathing the same air, having the same exercise, the same habits, the same food. The plague patient deposited in a European lazaretto becomes the cause which developes in others the affection from which he is suffering." I have stated some of the facts upon which these conclusions are founded. Many others may be found in the work to which I have referred. They were quite convincing to a Commission, who examined the subject with extreme care, patience, and impartiality. The members were gentlemen who had no personal interests at stake in the decision of the question. They neither sought to gain or retain any official position, either by the abrogation or the conservation of the quarantine laws. I think, therefore, we must accept their conclusions, and agree that as plague may be imported, and may extend withis the walls of a lazaretto, it is certainly a rise precaution to endeavour to prevent it from extending BEroxd those walls. Since 1837, the period when the mitary Board was established at Constantinople, the only pheges caces obcerved there have been in the lazaretto.
These were incontestably imported, and did not extend beyond the walls. These very facts have also been observed since 1838, in Smyrma, in Greece, and in Syra, the principal lazaretto of the Grecian archipelago.

Now, any one who has visited Greece, Barbary, and Turkey, will scarcely be inclined to report that the exemption of the inhabitants from the plague, since the establishment of quarantine regulations, has been owing to any great improvement in their sanitary condition. The houses and streets are as close, small, and dirty as ever; and the habits of the people unchanged in most respects. But quarantine has been established. When a ship has arrived from an infected port, it has been kept under observation, and if any plague patient arrived, he was kept within the walls of the lazaretto. In Turkey, the regulations were established at Constantinople and Smyrna in 1838. There has been no plague since-an interval of sixteen yearsexcept within the walls of the lazaretto. Surely this is a boon conferred by simple precautions upon a people, when we remember that, in $1812,3,000$ persons died daily in Constantinople alone, and 1,500 daily in 1834 and 1836 , only two years before these precautions were carried into effect.

In the last epidemic at Smyrna, between 30,000 and 40,000 were cut off-one-third of the entire population. I say, therefore, now, as I wrote in 1849 : "Experience has most fully established the great efficacy and real security to be derived from quarantine regulations when properly practised. Until the last twelve years, plague was so regularly a yearly visitor in the Levant, that it was believed to be indigenous in the whole Ottoman dominions. Russia occupied some of the Turkish provinces, the sanitary condition of which, as far as regards the local origin of disease, has not been much ameliorated by the change of dynasty; but quarantine was established, importation of plague was prevented, and these districts have since been as free from plague as the rest of Europe. Since the new kingdom of Greece has been separated from Turkey, and plague has been kept from its seaports by quarantine, no plague has been known in the kingdom, although those best acquainted with the country know that no other sanitary improvements of importance hare been effected. In the Barbary States, since quarantine has been established, no plague has existed. Formerly it was almost yearly imported by pilgrims, on their return from Necea. A gain, during the last sixteen years, quarantine has been established in Constantinople itself; several cases of plague have been imported and confined in the lazaretto ; the disease has spread in the lazaretto, but not beyond the walls; and the city has remained free from a disease, which before quarantine was practised, was so preralent, that no one doubted that it was of local origin. Those who know Constautinople, know that, if filth, and crowding, and defective sewcrage could produce plague, there it would certainly be in abundance." Yet there has been none except within the lazaretto. I claim, therefore, for these regulations an enormous saving of human life, infinitely overbalancing any pecuniary mischief caused by impediments to commerce, or any personal inconvenience to which travellers have been subjected. I fully admit that great loss and very unnecessary inconvenience has resulted from improper regulations, but I say that the true friend of humanity would seck to refi, $m$ what was improper, not to abolish an entire system which had done incalculable service. I say, further, that many authors who have written upon this subject of quarantine hare grossly overstated the inconvenience to which they have been obliged to submit, and that some of those who have described the system pursued in our lazarettos.hare proved by their very descriptions that they never could have visited any one of these establishments, and that they are inconceivably ignorant of the manner in which the quarantine regulations are carried into effect. For instance, in the report of Quarantine presented by the Gencral Board of Health to both Houses of Parliament in 1849, the reporters say: "If, as is generally agreed, confinement in a foul atmosphere can convert common fever into pestilence, and ventilation and dispersion can dissipate any contagion, then quarantine 
rinet be not only neoleas but pernicious, since the in mariable feet of quarnitine ss hitherto practised in all conntries hin been the congregation and confinement of the sick and of those who, though not actually sick, are suspected to of those who, the seeds of disease, requiring only a for days or hours for their development, - the congregition and confinement of such persons in a limitod space, often in a filthy ahip and an unhealthy locality, and always under circumstances calculated to excite apprehension and alarm, - conditions in the highest degree favourable to the generation and spread of disease: it follows that quarantine, instead of guarding against and preventing disease, fosters and concentrates it, and places it under conditions the most favourable that can be devised for its general extension; and therefore must not only fail to accomplish its object, but tend to produce the very calamity which it endesvours to prevent." (p. 61.)

Now this description of the practice of quarantine "in all countries," after having visited the principal European lararettos in the Mediterranean, I do not hesitate to state, is totally and entirely contrary to the truth. In no lazaretto for many years past have patients been congregated or confined in a limited space. On the contrary, all suspicious cases of sickness which occur on board ship are removed on shore, are placed in separate and well-ventilated rooms, and attendants are placed there with them. This is the invariable custom; and therefore the conclusion that quarantine fosters and concentrates disease is unfounded and untrue. I have been on three separate occasions in charge of small-pox patients in a lazaretto, for periods ranging from sixteen to twenty-one days. In every case the patients were removed from the ships as soon as they arrived, they were sent on shore to separate and well-ventilated rooms, and I, with nurses, was kept with them in quarantine until all danger of propagating the disease had passed off. Now, can any reasonable being doubt that in this way small-pox was prevented from spreading among other men on board the ships; or that if these precautions had not been taken, the seamen, and through them the whole neighbourhood might have suffered severely for a long period? The ill effects of the neglect of these precautions was most strongly evinced in 1830, when the small-pox was distinctly proved to have spread from the Naval Hospital at Malta to the home of the person who washed the patient's linen, and then over the greater part of the island. It extended itself rapidly, and did not cease until the following year, 10,351 persons having been attacked, of whom 1503 died. It was proved to have been imported from Greece in H.M.S. Asia, there being no small-pox in the island before the arrival of this ship; and there can be little doubt that the subsequent immunity of the island has been secured by the quarantine regulations, which were neglected in this unfortunate instance with the effect of destroying and disfiguring so many unfortunate persons.* And yet we are nauseated by philanthropical homilies upon the inhumanity of quarantine, and the reporters coolly tell us that the system places disease under conditions the most favourable that can be devised for its general extension. I repeat emphatically that in all the European lazarettos I have visited, and this includes nearly all those in the Mediterranean, quarantine regulations are carried out in exactly the opposite manner to that stated in the above paragraph. The sick are not confined in ships, but are immediately removed from the ships to the lazarettos; and these are not in unhealthy localities, but on islands or promontories fully exposed to the sea breezes. The sick are not congregated together, but are invariably separated from each other; and attendarits are placed with them, who must undergo the ame period of quarantine, and who know that their own anfety depends on the cleanliness and thorough ventilation the apartments and clothing of the sick.

I have trespassed already too long upon the time of the Bociety, but I cannot conclude without protesting against

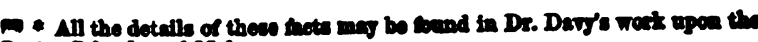
Teming Irlands and Yrite the sbenudity of those who talk of the riberivution of que rentine by enitary meacures, ss if quarantine when sor tionally practised was not a sanitary measure of the vary first importance. I contend that those who moat firmly believe in the good that quarantine can do and has dones but at the same time are anxious to remove its ipoonsistencies and to reduce it to a system based on science and experience, those, I sy, are the men who are the most earnest and practical supporters of other sanitary mearurea. They fully recognise the importance of drainage, rentiletion, and cleanliness; the necessity for improving the dwellings of the poor, and labouring hard to raise the social condition of the people; but they say, at the same time, do not neglect another great means of preserving health; do not, in case of contagious epidemics, hesitate to separate the sick from the healthy; not by crowding the sick together, but by separating them from each other in well ventilated institutions, and thus prevent them from communicating the disease under which they labour to the rest of the community. Bo far from this exciting alarm, as the opponents of quarantine assert, I maintain that it is the very best mode of tranquillising the public. Let us suppose ourselves in a sea port or an island, and that a ship arrived with plague on board, I would ask, is the population of that place likely to be more alarmed by hearing that the crew are at liberty to wander through the town or island, or that the sick have been confined in one part of a lazaretto, and the healthy in another; that the ship has been cleansed, and that all persons engaged about her have been kept under observation until all danger of the spreading the disease has ceased ?

Common sense can give but one answer to this. Yet this is the system which is condemned by the author of the paper which has led to this discussion, because it has been imperfectly and inconsistently carried out. I trust, however, that this Society will recognise the real good it has effected, even under the disadrantage of all these imperfections and inconsistencies, and will continue (while assisting us to obtain every necessary reform) to oppose the ing us to obtain institution which has infinitely orerbalanced the very great and unnecessary loss and inconvenience its operation has led to, by repeatedly preventing the introduction of contagious diseases into healthy communities, and by checking their progress after introduction,-in both ways effecting an incalculable saving of human life, thereby adding another to the vast boons which medicine has conferred upon mankind.

(30, Brook Street, Angust 1854.

)

\section{CLINICAL NOTES ON CHOLERA.}

By W. LAUDER LINDSAY, M.D., late Resident Physician of the Surgeon Square Cholera Hospital, Edinburgh.

[Continued from page 676.]

POST MORTEY YOVEXENTS AND RLETATION OP TRMPBRATUBE IN CHOLBRA PATIENTS.

Two classes of phenomena have been frequently noticed and described as occurring immediately after deaths during the collapse stage of the disease, vir.: tremulous and other morements of many of the smaller muscles of the body, and a sudden and general rise in the temperature of the surface. Specimens of the former I have distinctly seen in several cases; the latter I have by no means noticed to the same extent that it has been observed by others. The morements referred to consist in a slow and gradual flexion or extension, or both alternated; or in tremors or spasmodic sudden jerks, of various degrees of intensity, of the muscles of the jars, face, feet, and hands, and sometimes, though seldom, of the limbs and trunk. I have frequently noticed a quivering of the lips, varying in intensity or duration; tremors or jerts of the masseters, or contractions 80 forcible as to produce a churning or grinding of the teeth; a lateral anving motion of the lower $\mathrm{j} w$, or a firm clenching together of the jawe. In coms of the latter carces, the noive produced by the 